\title{
Sociocultural-Interactive Learning Strategies Employed by Students of Social Science and Engineering Studies
}

\author{
Yulianto Chandra \\ English Department, Faculty of Languages and Literature, Petra Christian University \\ Siwalankerto 121-131, Surabaya 60236, INDONESIA. \\ Email: yuliantoc1996@gmail.com
}

\begin{abstract}
This study aims to find how frequently employed are Sociocultural-Interactive (SCI) learning strategies by high-proficiency students of English for Academic Purpose at Petra Christian University in Surabaya, Indonesia. The study's theoretical framework is from Oxford's (2011) S R Model. To know the employment frequency of the strategies, questionnaire was distributed to 33 students classified as high-proficiency students. These students were divided into two groups based on the fields of study: social science and engineering. Descriptive statistics was used to see which strategy is more frequently used. Furthermore, to see if there is a significant statistical difference between the two groups, Independent $\mathrm{T}$ Test was conducted. The findings suggested that although, in general, social science students used SCI strategies more frequently, there was no significant statistical difference between the two groups regarding their employment of the strategies. Additionally, the findings revealed the SCI strategies have not been maximally used in learning English.
\end{abstract}

Keywords: learning strategies, sociocultural-interactive, high-proficiency, fields of study

\section{INTRODUCTION}

Literature addressing the magnitude of learning strategies in the development of second language learning is never outdated. Learning strategies are defined as deliberate use of means enhancing the students' learning (Scarcella and Oxford, 1992, as cited in Oxford, 2003). Scrutinizing the learning strategies of second or foreign language learners is not easy as each individual differs in the use of the learning strategies. However, in-depth knowledge regarding this subject matter has been seen important for both teachers and learners. It is claimed that understanding the learning strategies is beneficial for the teachers as they can help the learners achieve better performance in their learning, especially learners who have lower proficiency; and for learners as they can be in total control of their own learning as long as the learning strategies used fulfill three conditions; that the learning strategy must be relatable to the existing L2 task; that the learning strategies must tally with the students' learning style; and the effective employment of the strategy and the ability of the students to link it with other pertinent strategies (Oxford, 2003).

As second or foreign language learners are in the process of learning the target language the language being learned - they would need to use learning strategies that could help them carry out tasks and solve linguistic problems or insufficiencies they encounter along the process. Oxford (2011) proposes a model called $S^{2} R$ Model which displays the three essential dimensions in language learning; cognitive, affective and sociocultural-interactive. This model is designed to give clear picture of what dimensions occupying the pivotal position in the language learning and influencing the success of language learning.

Among the three elements, the writer is interested to see the sociocultural-interactive dimension as it encompasses interactional, social and cultural aspect in language learning. This means that this particular dimension requires learners to approach learning from the natural perspective. Oxford (2011) further explains that transpiration of learning in the natural setting leads learners to rely not on themselves only but also on other people the learners meet in their surrounding - in this sense, they may want to interact and collaborate with others, seek help, continue social interaction even when knowledge gaps arise, and deal with sociocultural issues of identity and power. In short, in the perspective of SCI dimension, strategic learners are required to exploit the social and cultural resources made available by the other people in the natural setting to learn a language. All 
of the actions mentioned are done by the learners with one goal in mind; developing proficiency in the target language.

More importantly, this study attempted to find the learning strategies used by highproficiency learners. High-proficiency learners are claimed to be the epitome because they are aware of the strategies they use to cope with hurdles; therefore, providing good example for the less proficient learners. A study conducted to analyze the use of language learning strategies by the students in China shows that successful (High-proficient) learners in China tend to deploy more strategies and more refined strategies in learning English as a second language (Cheng, $\mathrm{Xu}, \& \mathrm{Ma}$, 2007). Another study done by Gerami and Baighlou (2011) reveals that successful learners are particularly aware of the varieties of learning strategies and possess ample knowledge to apply them to their English language learning process. With the two study being explained, it is safe to say that high-proficient learners can be used as the sample of the present writer's study in order to further investigate what strategies can best be used by learners in order to become more proficient in learning English.

The writer of this study mainly focuses on the sociocultural-interactive learning strategies used by students of different fields of study in a private university in Indonesia. The fields of study are divided into two categories of science; social science and engineering - which is classified as part of formal science. Specifically, this study is orchestrated to find 1) the sociocultural-interactive learning strategies used by high-proficiency learners of social science studies, 2) the socioculturalinteractive learning strategies used by high-proficiency learners of social science studies, and 3) the statistical difference between the two populations.

\section{SOCIOCULTURAL-INTERACTIVE LEARNING STRATEGIES}

\section{Interacting to Learn and Communicate}

The first of the three strategies of SCI learning strategy is "interacting to learn and communicate" (Oxford, 2011). The accentuation of this strategy is basically on how the interaction with interlocutors can help learners to reach the goal of a successful second language mastery. "Interacting to learn and communicate" has several basic functions; 'interacting online or in person'; 'working with a mentor or tutor'; and 'asking for explanation', 'asking for clarification', 'asking for verification', 'asking for repetition', 'asking question nonverbally'. The following extract gives an example for this particular strategy.

"I work with a mentor who is a native speaker of Hungarian and who has lots of patience with me,"

(Oxford, 2011, p. 88-89)

The extract above is considered as 'Interacting to Learn and Communicate' because it reflects one of the 'working with a mentor or tutor'.

\section{Overcoming the Knowledge Gaps in Communicating}

"Overcoming the knowledge gaps in communicating" comes as the second strategy of SCI (Oxford, 2011). With this strategy, learners use their existing language resources or other methods to keep the conversation going with the people they are talking to. 'Using other words to communicate, despite the gap in knowledge', 'using physical cues to continue to communicate', 'changing the topics (topic avoidance)' and 'pretending to understand' are all the basic functionks of this strategy. The following extract provides an illustration for this second strategy.

"I use a synonym or even an antonym if I cannot think of the word I need,"

(Oxford, 2011, p. 89)

The above extract is particularly classified as an example for 'overcoming the knowledge gap in communicating' due to reflecting one of its basic functions; that is 'using other words to communicate despite the gap in knowledge'

\section{Dealing with Sociocultural Contexts and Identities}

The last strategy of SCI is "dealing with sociocultural contexts and identities" (Oxford, 2011). By availing themselves of this strategy, learners attempt to employ its basic functions; that 
are 'imitating cultural behaviors'; 'exploring the meaning of social roles, identity, power, and the media'; 'considering what is expected for entry into the imagined community'; 'using counterdiscourses to gain sociocultural acceptance'; and 'exploring sociocultural meanings about silence, body language, and social customs'. The next extract illustrates the third strategy.

"I especially focus on the amount of silence and the presence or absence of interruptions that are expected in conversation and try to figure out more about the culture based on this,"

(Oxford, 2011, p. 89)

The example shown in extract 2.3 illustrates 'dealing with sociocultural contexts and identities' since it reflects one of the basic functions; that is "exploring the sociocultural meanings about silence".

\section{METHODS}

This study was approached quantitatively. Quantitative research is an approach involving numbers, quantification, variables, generalizability and statistics to address a research problem or objective, and it typically requires a large sample size (Dörnyei, 2007). Since the approach of the writer's study meets the definition, the writer's study is labelled as quantitative study.

The subject of this study is 33 students who earned A for their English for Academic Purpose (EAP) of 2018 even semester (February - June, 2018). These students are classified as highproficiency learners due to their obtained final scores from the class.

Likert-scale questionnaire with six scales was distributed to the students. There were 21 statements given to the students and the students had to rate the frequency of their use of the SCI strategies. The statements were adapted from the statements elaborated in Oxford (2011, p. 132-136). The writer used descriptive statistics to analyze the first and second research questions. For the third research question, the writer conducted Independent $\mathrm{T}$ Test by using a software for Windows called Statistical Package for Social Sciences (SPSS).

\section{FINDINGS AND DISCUSSIONS}

\section{High-Proficiency Social Science Students' Use of SCI Strategies}

The first strategy of SCI is 'interacting to learn and communicate and it was found that the highest percentage of interacting to learn and communicate is $31.2 \%$ at "almost always" area. Whereas, "never" has the lowest percentage; $2.1 \%$. Social science learners are aware that learning through interacting is crucial and is aware of the circulation of input and output when interaction is transpiring, which means that learners receive comprehensible input when communicating and, at the same, the exploitation of the interacting to learn and communicate leads them to retrieve the input, that has been processed through previous interacting experiences, from their arsenal and produce it as output. This is aligned with the idea that interaction affects the procurement of L2 in terms of the grammatical and lexical points, and semantic and pragmatic meanings (Ellis, 1991)

As for the second strategy, it was found that the social science respondents sometimes use 'overcoming the knowledge gaps in communicating' as 33.3\% belong to that frequency. There are several conclusions that can be made from this finding. First, since knowledge gaps arise due to insufficient linguistic repertoire and communicative competence to perform communicative tasks, and lack of rudimentary grammatical points, vocabulary items and subtle semantic or pragmatic nuances; there is a high possibility that learners rarely find all these difficulties in performing communicative tasks with their interlocutors as their proficiency is considerable high. The second conclusion is that social learners may not be aware of these hurdles. Schmidt (1995), through his noticing hypothesis, says that L2 learning involves awareness and that improvement of learners' accuracy, fluency and pragmatic competence transpires when they are aware of what happens during communication with their counterpart. However, when learners are not aware, they may not be able to use strategies to overcome the hurdles; therefore no learning ensues. The third conclusion - rather presumptive but evidenced - that can be made is that social science learners' action in communication can be identified as an attempt to learn or use. Rejection towards the polarity of language use and language learning is made by Oxford (2011) to further establish the notion that learning involves use and use can be for learning. However, due to the nature of the two closely 
linked elements being inseparable, learners may not know which features of the communication can be taken as means for learning improvement (Bialystok \& Smith, 1985).

For the third strategy, the writer found that the biggest percentage of high-proficiency social science students' use of dealing with sociocultural contexts and identities is $25 \%$ at, again, 'sometimes' as demonstrated by table 4.2. The indication of this is that the social science students may not take into consideration the sociocultural aspects of language learning when they learn English. The learners may still use this particular strategy to learn although not fully using it.

\section{High-Proficiency Engineering Students' Use of SCI Strategies}

For the first strategy, the highest percentage is at $27.4 \%$ (often). The writer found that engineering students, similar to social science students, tend to use interacting to learn and communicate as means of acquiring the skills and knowledge of L2. This demonstrates engineering students are not indifferent towards interaction for learning, meaning that these learners are still aware of the importance of interaction and very much rely upon interaction. Nevertheless, the highest percentage of this SCI strategy practically implies that engineering learners are a bit behind the social science students as they generally "often" employ interacting to learn and communicate in their English learning.

The writer of this study also found that learners from engineering disciplines tend to use 'overcoming the knowledge gaps in communicating' because 'often' seized the biggest percentage with $27.4 \%$. Using overcoming the knowledge gaps in communicating, especially if it reaches the dominant level, signifies that engineering are able to overcome communicational impediments that occur while communicating with the interlocutors. These hurdles are insufficient linguistic repertoire and communicative competence to perform communicative tasks, lack of rudimentary grammatical points, vocabulary items and subtle semantic or pragmatic nuances (Finegan, 2004; Oxford, 2011). Engineering learners are aware that these hurdles are of existence for them to learn. Ergo, the learners perform several tasks like paraphrasing skills, borrowing, changing topics, approximating the message, coining new words, and mimicking/gesturing to open up the door for the continuation of the communication (Oxford, 2011).

As for the third strategy, the biggest percentage stands at $29.1 \%$ for sometimes; meaning that engineering students sometimes or rarely heed the significance of cultural elements in L2 learning. Not only that the dominant percentage is sometimes but the majority of the respondents seem to have consensus that cultural understanding might not be of importance for them to learn English as the smaller frequency area accounts for 59.8\% of the result. This suggests that engineering students may not find sociocultural aspects contributing to their L2 learning. Oxford (2011) explicates that among the three SCI learning strategies, dealing with sociocultural contexts and identities is fundamentally the most demanded strategy and occupies the highest level which implies that the learners must have the awareness and the ability to deploy this strategy. Therefore, it is safe to say that the engineering learners are not aware of the cultural issues in learning English and are not in the level where they can use this strategy to cope with cultural issues.

\section{Significant Statistical Difference between High-Proficiency Social Science and Engineering Students in Using SCI Strategies}

There are two hypotheses of the study; the null hypothesis and the alternative hypotheis. The null hypothesis, symbolized by Ho, is that significant difference in the use of SCI strategies by highproficiency learners of social science and engineering studies is of nonexistence. Whereas, the alternative hypothesis, generally symbolize by Ha, implies that there is a significant difference in the use of SCI strategies by high-proficiency learners of social science and engineering studies.

Table 1: Results of the independent $t$ test. 


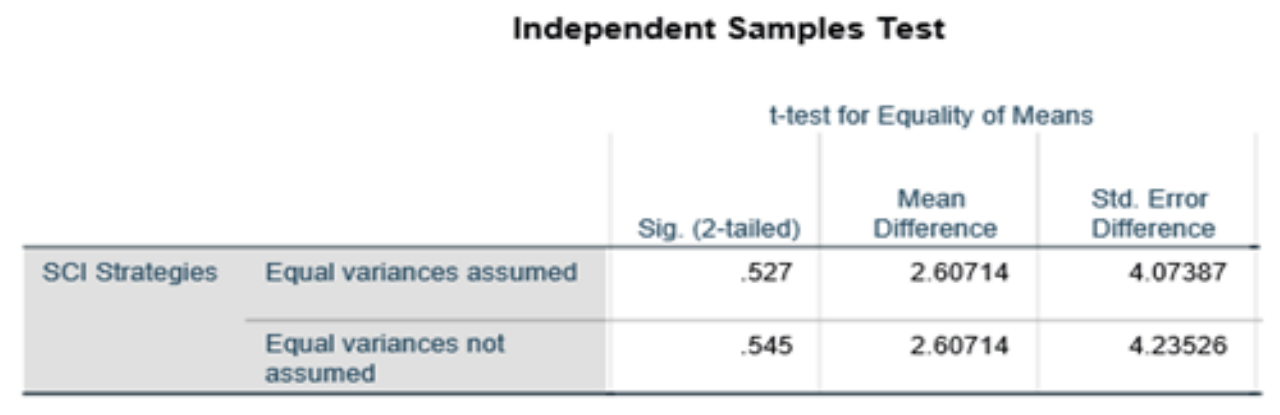

In order to know if there is a significant difference between high-proficiency learners of social science and engineering in terms of their use of SCI learning strategies, the Sig. (2-tailed) must be interpreted. The interpretation of the value will determine the acceptance or rejection towards the null hypothesis. If the value is bigger (>) than 0.05 , Ho is accepted and $\mathrm{Ha}$ is rejected. On the contrary, if the Sig. is smaller $(<)$ than 0.05 , Ho is rejected and Ha is accepted.

As can be seen on the table above, the value under Sig. (2-tailed) and on the 'equal variances not assumed' is 0.545 ; meaning that the significance value is larger than the significance level, 0.05 . Ergo, it can be concluded that Ho is accepted and Ha is rejected. This simply implies that there is no significant difference in the deployment of SCI strategies by the two groups of respondents.

\section{Overall Analysis}

Table 2: Overall Frequency for SCI Strategy as a Whole

\begin{tabular}{|c|c|c|c|c|c|c|c|}
\hline \multirow[t]{3}{*}{ No } & \multirow[t]{3}{*}{ SCI Strategies } & \multicolumn{6}{|l|}{ Scale } \\
\hline & & Never & Almost Never & Sometimes & Often & $\begin{array}{l}\text { Almost } \\
\text { Always }\end{array}$ & Always \\
\hline & & \multicolumn{3}{|c|}{ "Less frequently used" area } & \multicolumn{3}{|c|}{ "More frequently used" area } \\
\hline \multirow[t]{2}{*}{1} & \multirow[t]{2}{*}{ Social Science } & $6.8 \%$ & $13.1 \%$ & $23 \%$ & $21.8 \%$ & $25.4 \%$ & $9.9 \%$ \\
\hline & & \multicolumn{3}{|c|}{$42.9 \%$} & \multicolumn{3}{|c|}{$57.1 \%$} \\
\hline \multirow[t]{2}{*}{2} & \multirow[t]{2}{*}{ Engineering } & $5.7 \%$ & 15.6 & $26.5 \%$ & $23.4 \%$ & $20.2 \%$ & $8.6 \%$ \\
\hline & & \multicolumn{3}{|c|}{$47.8 \%$} & \multicolumn{3}{|c|}{$52.2 \%$} \\
\hline
\end{tabular}

The result of this study found that social science learners, despite their high-proficiency, still do not maximally use the sociocultural-interactive strategy in learning English. Although their use of the SCI domain is not yet maximal, they still used SCI strategies more frequently compared to engineering students. As displayed in table 4.9, the use of SCI learning strategies by social science students is more dominant on the more frequently used area; as the accumulated percentage of the area reaches $57.1 \%$. Not only that the SCI strategies social science students use to learn English are generally on the more frequently used area, the highest percentage is also on the 'almost always'; 25.4\%. Moreover, this study's findings of engineering students' use of SCI strategies showed that their use of SCI strategies is just as not maximal as that of social science students, although both groups are classified as highly proficient learners. This claim is supported by the fact that the highest frequency scales - 'always' - of both groups do not reach double digit percentage. Nevertheless, the lowest scales of both groups also do not reach double digit percentage, meaning that their use of SCI in English learning is neither maximal nor minimal; only moderate. However, compared to social science students, engineering students only reached $52.2 \%$ in the more frequently used area; while the highest frequency stands at 'sometimes' with $26.5 \%$. This simply implies that despite the higher frequency area being more dominant, the engineering students are still not maximal in using SCI strategy, a little bit more 'not maximal' compared to social science students. It also implies that the students of social science studies are more advanced in using this learning strategy compared to engineering students although both groups are similar in proficiency.

The learners' use of the SCI strategies which is still far from maximum was further supported by statistical findings of the third research question which is about the significant difference between 
social science and engineering students. It was found that both groups are indeed similar and almost identical in terms of their use of SCI strategies because there is no significant difference between the two groups. Therefore, it can be said that although the learners from both categories of science are of high-proficiency, the use of SCI domain which encompasses the cultural and social aspects has not reached maximum level. As previously mentioned in the second chapter of this study, communication and culture, which are two elements included in SCI domain, are two important aspects for second language acquisition. In order to gain ample linguistic proficiency, understanding of the role of these two elements comes as pivot.

\section{CONCLUSION AND SUGGESTION}

This study concludes that there is no significant difference between social science and engineering students when employing sociocultural-interactive learning strategies. It is shown from how the significance value indicates the insignificancy between the two populations. However, although all of the three strategies of SCI were found to be used by all students, differences are found in regards to the students' frequency of using the specific strategies of sociocultural-interactive learning strategies. The predisposition of the students' use is more leaning towards either 'sometimes' or 'often'. Whereas, one learning strategy from sociocultural-interactive domain, which is 'interacting to learn and communicate' appears to be 'almost always' used by social science students. This simply implies that, although none of the strategies is leaning towards the least frequently used strategies, indicated by 'never' and 'almost never', the use of the socioculturalinteractive learning strategies by the students, in order to cope with the learning-process problems, is still not maximal. Another proof of the moderate use of sociocultural-interactive learning strategy can be seen from how none of the strategy reaches highest frequency, indicated by 'always'. Therefore, the notion that high-proficiency learners use more refined strategies and are aware of the importance of such strategies that they use them more frequently compared to lower-proficiency learners, is not true. This study also indicates that different fields of studies are not necessarily different concerning the use of sociocultural-interactive strategies.

Other than explaining the students' frequency of using the learning strategies and the insignificancy of the use between the two groups, the findings of this study also reflect how English learning has not fully been socially and culturally approached; meaning that most learners, despite being highly proficient, have not seen social and cultural aspects as possible means to achieving language proficiency and coping with problems in the students' quest for good mastery of English. While cultural and social aspects are practically embedded in a language, students may have not reached the level where they can dig more into the cultural and social aspects of language and develop their linguistic from those aspects. On the other hand, high-proficiency learners seem to convict that interacting may be more of a useful learning strategy or device to advance in their learning compared to the aforementioned aspects. Hence, the findings of this study expose the desideratum for provoking awareness to English as second language learners that social and cultural aspects, not solely the interactional aspects of learning, are as much important in learning a target language, especially English.

Since this study examined 33 students, it is suggested that future studies that aim to discover more about the sociocultural-interactive learning strategies take on larger populations. Considering that this study mainly focuses more on the students, it is also suggested that researchers take into consideration the possible influencing factors such as teachers and learning materials. These two components may influence students' preferred use of sociocultural-interactive learning strategies, especially most students, in Indonesian context, acquire their second language proficiency through formal teaching and instructions in classes. By heeding the importance of these factors, future researchers may be able to see that even self-directed strategies can be influenced by other factors.

Furthermore, another suggestion is given on the approach of the study. If this study is approached quantitatively, it would be better for future researchers to approach this phenomena through qualitative view by conducting interview or open-ended questionnaire. By approaching this in a qualitative manner, it is expected that future researchers can see the use of socioculturalinteractive strategies with more details and to prove their true proficiency as academic scores themselves can be influenced by many underlying factors. 


\section{REFERENCE}

Bialystok, E., \& Smith, M. S. (1985, January 1). Interlanguage is not a state of mind: An evaluation of the construct for second-language acquisition. Applied Linguistics, 6(2), 101-117. doi:https://doi.org/10.1093/applin/6.2.101

Cheng, X. L., Xu, K., \& Ma, Y. (2007). A Survey of Engineering Student's Use of English Language Learning Strategies. The Journal of Asia TEFL, 4. Retrieved September 2, 2018, from http://www.asiatefl.org/main/download_pdf.php?i=302\&c=1419313915

Dörnyei, Z. (2007). Research methods in applied linguistics: Quantitative, qualitative, and mixed methodologies. Oxford: Oxford University Press

Ellis, R. (2005). Measuring implicit and explicit knowledge of a second language. A psychometric study. Studies in Second Language Acquisition, 27, 141-172.

Finegan, E. (2004). Language: Its Structure and Use (Fifth ed.). Michael Rosenberg. Retrieved October 2, 2018, from http://staffnew.uny.ac.id/upload/132107096/pendidikan/Book+one+for+Int.pd f

Gerami, M. H., \& Baighlou, S. M. (2011). Language Learning Strategies Used by Successful and Unsuccessful Iranian EFL Students. Procedia - Social and Behavioral Sciences, 29, 15671576. Retrieved December 3, 2018, from https://www.sciencedirect.com/science/article/pii/S1877042811028667

Oxford, R. L. (2003). Language learning styles and strategies: an overview. Retrieved April 29, 2018,from http://web.ntpu.edu.tw/ language/workshop/read2.pdf

Oxford, R. L. (2011). Teaching and Researching Language Learning Strategy. New York:

Longman

Schmidt, R. (2010). Attention, awareness, and individual differences in language learning. Retrieved October 2, 2018, from http://nflrc.hawaii.edu/PDFs/SCHMIDT\%20Attention\%2C\%20awareness\%2 C\%20and\%20individual\%20differences.pdf 